\title{
Evaluation of Flaxseed Formulation as a Potential Therapeutic Agent in Mitigation of Dyslipidemia
}

\author{
Sonali Saxena, Charu Katare
}

Background: Cardiovascular diseases (CVDs) are an increasing health problem all over the world. The search for natural hypolipidemic agents that can be used besides the synthetic drugs is still in its experimental stage. Plant seeds, particularly flaxseed (Linum usitatissimum), which is a rich source of $n-3$ fatty acids, lignans and phenolic compounds, have also received increasing attention for their potential role in preventing lipid disorders. The present study was undertaken to evaluate the therapeutic potential of flaxseeds in dyslipidemia.

Methods: The study included 50 dyslipidemic subjects selected by purposive random sampling and were divided into two groups, a control and an experimental group. Both the groups were prescribed similar dietary guidelines. Subjects in the experimental group received $30 \mathrm{~g}$ of roasted flaxseed powder for 3 months. Anthropometric parameters, blood pressure, and blood lipid profile were estimated before the study and after completion of the study.

Results: $\quad$ Flaxseed supplementation resulted in a remarkable improvement in anthropometric measurements, blood pressure, and lipid profile in the experimental group. Body

\section{At a Glance Commentary}

Scientific background of the subject

Health and plant foods have an age old association. Several plant foods are reported to have nutraceutical functions. Flaxseed is a rich source of Alpha linolenic acid (ALA), fiber and lignans, making it a potentially attractive functional food for modulating cardiovascular risk.

\section{What this study adds to the field}

Functional foods and nutraceuticals may provide a means to reduce the increasing burden on the health care system by a continuous preventive mechanism which is cost effective compared to modern drug therapy. Nutritional supplementation of flaxseed roasted powder may prove very effective and convenient aid in mitigative effect on dyslipidemia. weight and body mass index (BMI) of the experimental group were significantly reduced $(p<0.01)$. A lowering of systolic and diastolic blood pressure $(p<0.05)$ was also recorded in the dyslipidemic subjects. Concomitantly, a highly significant reduction $(p<0.01)$ in total cholesterol, triglycerides, low density lipoprotein-cholesterol (LDL-C), and very low density lipoprotein-cholesterol (VLDL-C) levels, with simultaneous elevation $(p<0.01)$ in high density lipoprotein-cholesterol (HDL-C) levels was observed. Improvement in lipid levels resulted in reduction of atherogenic indices.

Conclusions: The supplementation of roasted flaxseed powder for 3 months improved the BMI, blood pressure, and lipid profile of dyslipidemic subjects, thus exhibiting cardio protective effect.

(Biomed J 2014;37:386-390)

Key words: antiatherogenic, dyslipidemia, flaxseed, polyunsaturated fatty acids

$I_{\text {in }}^{\text {n }}$ $\mathrm{n}$ recent years, plant foods have attracted a great deal of interest among consumers and health care professionals for their potential benefits on human health. This is based on accumulated data from epidemiologic as well as nutritional intervention studies in humans and animals. Plant seeds, particularly flaxseed (Linum usitatissimum), have also received increasing attention for their potential role in preventing lipid disorders. Abnormal blood lipids, known as dyslipidemias, are one of the major risk factors for heart disease. ${ }^{[1]}$ Cardiovascular diseases (CVDs) are a leading

From the Department of Food and Nutrition, Government Kamla Raja Girls PG Autonomous College, Gwalior, Madhya Pradesh, India Received: Apr. 04, 2013; Accepted: Jan. 21, 2014

Correspondence to: Dr. Charu Katare, Department of Food and Nutrition, Government Kamla Raja Girls PG Autonomous College, India. Gwalior - 474 001, Madhya Pradesh, India. Tel: 91-0751-2321054; Fax: 91-751-2325396; E-mail: cskatare@ gmail.com

DOI: $10.4103 / 2319-4170.126447$ 
cause of death today. There are now significant research data suggesting that Coronary Artery Disease (CAD) can be altered or prevented in large part by three major lifestyle changes. These three factors are nutritional modification, incorporating exercise into our daily lives, and eliminating smoking. ${ }^{[2]}$ Dietary interventions have recently received attention as effective strategies to prevent, mitigate, or reduce the risk factors of some diseases. ${ }^{[3]}$ Some studies have shown that whole flaxseed lowers serum cholesterol in animals and humans. ${ }^{[4]}$ Flaxseed is the richest plant source of omega-3 fatty acid ( $\alpha$-linolenic acid or ALA) and the phytohormone lignans. It is also an essential source of high-quality protein and dietary fiber. Additionally, flaxseed has the potential to be a source of phenolic compounds. Because of the beneficial physiological effects of its components, this seed is considered a functional food. ${ }^{[5]}$ The present study was undertaken to evaluate the therapeutic potential of flaxseed formulation by incorporating it in the diet of dyslipidemic subjects.

\section{METHODS}

\section{Preparation and sensory evaluation of flaxseed formulation}

The formulation to be supplemented was prepared by cleaning and roasting flaxseeds. It is reported that roasting effectively reduces the antinutritional factors like cyanogenic glycoside content of the flaxseeds ${ }^{[6]}$ as cooking destroys the enzyme that metabolizes the glycosides. ${ }^{[7]}$ Roasting imparts a nutty flavor to the powdered flaxseeds, thus improving its acceptability. Apart from having improved taste and flavor, roasted flaxseed powder is also found to have good shelf life. To improve the taste, a pinch of cumin powder, sugar, chili powder, and fresh lemon drops are added to roasted flaxseed powder.

\section{Sensory evaluation}

Sensory evaluation has been defined as a scientific method used to evoke, measure, analyze, and interpret those responses to products as perceived through the senses of sight, smell, touch, taste, and hearing, ${ }^{[8]}$ and is a major determinant in the subsequent adoption and use of the product. ${ }^{[9]}$ To determine acceptability of the formulation, it was presented to a panel of 12 judges comprising the faculty members of Department of Food and Nutrition and dyslipidemic subjects. The roasted flaxseed powder was organoleptically evaluated using nine-point Hedonic scale, ${ }^{[10]}$ and scoring was done for taste, aroma, chewing quality, and texture.

\section{Nutrient content}

Nutrient content per serving of the most acceptable formulation of flaxseed powder was calculated from the values given in nutritive values of Indian foods ${ }^{[11]}$ [Table 1].
Table 1: Nutrient content of roasted flaxseed formulation ${ }^{[11]}$

\begin{tabular}{lc}
\hline Nutrients/30 g & Quantity \\
\hline Energy $(\mathrm{kcal})$ & 171.0 \\
Protein $(\mathrm{g})$ & 6.09 \\
Crude fiber $(\mathrm{g})$ & 1.44 \\
Soluble dietary fiber $(\mathrm{g}) *$ & 0.36 \\
Insoluble dietary fiber $(\mathrm{g}) *$ & 0.72 \\
Lignan $(\mathrm{mg}) * *$ & 30.0 \\
LA $(n-6)(\mathrm{g})$ & 2.07 \\
ALA $(n-3)(\mathrm{g})$ & 5.41 \\
$*[41], * *[42]$, Abbreviations: LA: Linoleic acid; ALA: Alpha linolenic acid
\end{tabular}

\section{Selection of dyslipidemic subjects}

Fifty subjects between the ages of 40 and 60 years having dyslipidemia, who were regular visitors of hospitals or clinics, were recruited from various areas of Greater Gwalior by stratified random sampling (purposive) method. Subjects were required to have a values of pre-study fasting triglycerides (TGs) $>150 \mathrm{mg} / \mathrm{dl}$ or cholesterol $>200 \mathrm{mg} / \mathrm{dl}$ or low density lipoprotein (LDL) $>130 \mathrm{mg} / \mathrm{dl} \cdot{ }^{[12]}$ All the dyslipidemic subjects were divided into two groups: A control group and an experimental group, each consisting of 25 subjects. The methodology consisted of administration of a pre-tested questionnaire to the subjects to collect general information, viz., nutritional status data [height, weight, body mass index (BMI)], blood pressure, health complaints, socioeconomic status, dietary pattern, medical history, and lifestyle at the beginning of the study. Compliance was checked by fortnightly collection of dietary intake data by $24-\mathrm{h}$ recall method. The subjects included were not on medications for any chronic disease (cancer, CVD, diabetes mellitus, or even dyslipidemia). Persons who reported having taken lipid-lowering drugs or high-dose dietary supplements/ herbal supplements during the preceding 3 months were excluded. Pregnant and lactating mothers were also not included for the study.

Blood samples were collected from the selected subjects $12 \mathrm{~h}$ after the last meal was consumed. Plasma TG level was estimated by glycerol-3-phosphate oxidation-peroxidase method, ${ }^{[13]}$ total cholesterol (TC) by cholesterol oxidase and $p$-aminophenazone method ${ }^{[14]}$ and high density lipoprotein-cholesterol (HDL-C) level was estimated by phosphotungstate method. ${ }^{[15]}$ The LDL and very low density lipoprotein (VLDL) levels were calculated by Friedewald's equation. ${ }^{[16]}$ The atherogenic indices ${ }^{[17,18]}$ calculated were: Cardiac Risk Ratio $($ CRR $)=$ TC/HDL-C, Atherogenic Coefficient $(\mathrm{AC})=(\mathrm{TC}-\mathrm{HDL}-\mathrm{C}) / \mathrm{HDL}-\mathrm{C}$, and Athrogenic Index of Plasma [AIP $=\log (\mathrm{TG} / \mathrm{HDL})]$.

All the subjects were prescribed similar dietary guidelines and were asked to continue with their normal routine activity. The control group was not administered any supplementation, whereas the experimental group was asked to consume $30 \mathrm{~g}$ of roasted flaxseed powder every day with 
meals for a period of 3 months. At the end of the 3-month period, anthropometric parameters and blood pressure were recorded, followed by estimation of lipid profile. Study design and protocols were approved by the Institutional Human Ethics Committee. Statistical analysis of data was carried out by paired $t$-test using Microsoft Excel 2007.

\section{RESULTS}

Preventing the occurrence of CVD with nutritional interventions is an important therapeutic strategy, as indicated in several epidemiological studies. Recently, attention is being paid towards the use of flaxseed which is reported to reduce the risk of CVD because it is a rich source of ALA that has the potential to reduce $\mathrm{TGs}^{\left[{ }^{[19]}\right.}$ blood pressure, ${ }^{[20]}$ and CVD. ${ }^{[21]}$ Flaxseed is also rich in dietary lignans, a class of phytoestrogens documented to have lipid-lowering and antioxidant properties. ${ }^{[22]}$

In the present study, it was found that daily intake of $30 \mathrm{~g}$ of roasted flaxseed powder was well tolerated and modulated selected risk factors of CVD. A mean change of $2.89 \%(p<0.01)$ in body weight and $3.05 \%(p<0.01)$ in BMI [Table 2] was found in the dyslipidemic subjects consuming flaxseed supplementation. Flaxseeds are a good source of dietary fibers and a large proportion of these are water-soluble viscous fibers. ${ }^{[23]}$ Viscous fibers are reported to be effective in suppression of hunger. ${ }^{[24]}$ Dietary fibers may also play a role in body weight regulation through both hunger suppression and diminished nutrient absorption. ${ }^{[25]} \mathrm{In}$ a study, flaxseed mucilage was observed to be responsible for reduced growth of broiler chickens on comparing feeds with whole and demucilaged flaxseeds. ${ }^{[26]}$ Corresponding to our findings, the results of a study indicated that addition of flaxseeds to rye breads $(6 \mathrm{~g} / 100 \mathrm{~g})$ significantly reduced the digestibility of fat and energy in humans. ${ }^{[27]}$

In our study, flaxseed supplementation was associated with a significant reduction $(p<0.05)$ [Table 3] in systolic and diastolic blood pressure, with a mean change of $0.88 \%$ and $1.91 \%$, respectively. Results of our study are in agreement with a previous study which reports a decrease in diastolic blood pressure in men taking flaxseed lignin when evaluated against the men taking placebo. ${ }^{[28]}$ Yet another

Table 2: Effect of administration of roasted flaxseed powder on body weight and BMI

\begin{tabular}{|c|c|c|c|c|c|c|c|}
\hline \multirow[t]{2}{*}{ Parameter } & \multirow{2}{*}{$\begin{array}{l}\text { Study group } \\
(n=25)\end{array}$} & \multicolumn{2}{|c|}{ Before } & \multicolumn{2}{|c|}{ After } & \multirow{2}{*}{$\begin{array}{c}\text { Mean } \\
\text { change } \\
(\%)\end{array}$} & \multirow[t]{2}{*}{$p$ value } \\
\hline & & Mean & SD & Mean & SD & & \\
\hline \multirow{2}{*}{$\begin{array}{l}\text { Body } \\
\text { weight }(\mathrm{kg})\end{array}$} & Control & 76.32 & 7.30 & 75.90 & 7.23 & 0.55 & 0.846 \\
\hline & Experimental & 76.12 & 10.49 & 73.92 & 11.19 & 2.89 & $0.000 * *$ \\
\hline \multirow{2}{*}{$\begin{array}{l}\text { BMI } \\
\left(\mathrm{kg} / \mathrm{m}^{2}\right)\end{array}$} & Control & 28.90 & 4.21 & 28.70 & 4.35 & 0.69 & 0.916 \\
\hline & Experimental & 28.48 & 2.91 & 27.61 & 3.02 & 3.05 & $0.000 * *$ \\
\hline
\end{tabular}

study revealed the hypotensive effect of ALA, a natural precursor of the cardioprotective long-chain $n-3$ fatty acids, causing significant lowering of systolic and diastolic blood pressure levels. ${ }^{[29]}$ It has also been reported that omega-3 polyunsaturated fatty acid deficiency, particularly during the prenatal period, can cause hypertension in later life. ${ }^{[30]}$

Results of the present study indicated a remarkable improvement in serum lipids of the experimental group. A mean lowering of $16.19 \%(p<0.01)$ and $13.99 \%(p<0.01)$ was observed in total serum cholesterol and TGs. Similar changes $(p<0.01)$ in serum LDL and VLDL levels, with a mean change of $19.93 \%$ and $17.94 \%$, respectively, were observed at the end of 3 months [Table 4]. Lowering of lipid level was noticed in the control group also, though the effect was more pronounced in the experimental group, which may be attributed to flaxseed supplementation. These results did not vary markedly from a study which pointed out that flaxseed consumption decreased blood TC and LDL-C concentrations, and this effect was more apparent in studies that used whole flaxseed. ${ }^{[31]}$ Addition of flaxseeds to the diet partially mitigated the rise in circulating cholesterol levels induced by the cholesterol-enriched diet through its content of ALA. ${ }^{[32]}$ The results of our study are further supported by the findings of another study which proposes that increased bile acid synthesis is one of the major cholesterol-lowering mechanisms of flaxseed and that another component, besides its oil, contributes to its hypocholesterolemic property. ${ }^{[33]}$ Dietary flaxseed lignans, such as secoisolariciresinol diglucoside (SDG), also have demonstrated potent antioxidant and anti-atherogenic effects. ${ }^{[34]}$ A simultaneous mean elevation of $4.94 \%$ in the serum HDL level was also observed in our study [Table 4]. This result corroborates with the findings of a study which provided evidence that consumption of flaxseed significantly reduced TC and significantly increased HDL-C concentration. ${ }^{[35]} \mathrm{A}$ major risk factor for the development of CVDs is decreased plasma concentrations of HDL-C. ${ }^{[36]}$ It often accompanies diabetes mellitus, ${ }^{[37]}$ hypertension, and obesity. Researchers have shown that increase in plasma HDL-C concentration reduces cardiovascular risk. ${ }^{[38]}$

Low atherogenic indices are protective against coronary heart diseases. ${ }^{[39]}$ In the present study, a significant improve-

Table 3: Effect of administration of roasted flaxseed powder on blood pressure

\begin{tabular}{|c|c|c|c|c|c|c|c|}
\hline \multirow{2}{*}{$\begin{array}{l}\text { Parameter } \\
(\mathrm{mm} \text { of } \mathrm{Hg})\end{array}$} & \multirow{2}{*}{$\begin{array}{l}\text { Study group } \\
(n=25)\end{array}$} & \multicolumn{2}{|c|}{ Before } & \multicolumn{2}{|c|}{ After } & \multirow{2}{*}{$\begin{array}{c}\text { Mean } \\
\text { change } \\
(\%)\end{array}$} & \multirow{2}{*}{$p$ value } \\
\hline & & Mean & SD & Mean & SD & & \\
\hline \multirow{2}{*}{$\begin{array}{l}\text { Systolic blood } \\
\text { pressure }\end{array}$} & Control & 138.40 & 16.50 & 137.92 & 16.22 & 0.35 & 0.918 \\
\hline & Experimental & 135.76 & 13.64 & 134.56 & 12.27 & 0.88 & $0.044 *$ \\
\hline \multirow{2}{*}{$\begin{array}{l}\text { Diastolic } \\
\text { blood pressure }\end{array}$} & Control & 90.40 & 7.90 & 89.60 & 7.35 & 0.88 & 0.712 \\
\hline & Experimental & 88.0 & 6.45 & 86.32 & 6.34 & 1.91 & $0.034 *$ \\
\hline
\end{tabular}


ment $(p<0.01)$ in atherogenic indices was noted after intake of roasted flaxseed powder for 3 months [Table 5]. A study conducted in Turkey observed that AIP was the best predictor of hypertension, diabetes, and vascular events. ${ }^{[40]}$ Findings of this study indicated that there was appreciable improvement in selected CVD risk factors of subjects in the control group also, though the improvement was not as striking as in the experimental group. The control group and experimental group followed similar dietary guidelines and lived a sedentary life. Therefore, it may be concluded that nutritional supplementation with an appropriate dietary regimen can prove to be a very effective and convenient aid in the prevention of CVD in modern lifestyles. The limitation of this study is that since the control group was not administered any supplementation, the placebo effect of flaxseed supplementation cannot be excluded.

\section{Conclusion}

It is well known that the modification of lipid concentration is a useful approach to decrease cardiovascular mortality through prevention of development of atherosclerotic disease. In conclusion, incorporating $30 \mathrm{~g}$ of roasted

Table 4: Effect of administration of roasted flaxseed powder on blood lipid profile

\begin{tabular}{|c|c|c|c|c|c|c|c|}
\hline \multirow{2}{*}{$\begin{array}{l}\text { Parameter } \\
(\mathrm{mg} / \mathrm{dl})\end{array}$} & \multirow{2}{*}{$\begin{array}{l}\text { Study group } \\
(n=25)\end{array}$} & \multicolumn{2}{|c|}{ Before } & \multicolumn{2}{|c|}{ After } & \multirow{2}{*}{$\begin{array}{c}\text { Mean } \\
\text { change } \\
(\%)\end{array}$} & \multirow{2}{*}{$p$ value } \\
\hline & & Mean & SD & Mean & SD & & \\
\hline \multirow{3}{*}{$\begin{array}{l}\text { Total } \\
\text { cholesterol }\end{array}$} & & & & & & 1.81 & 0.365 \\
\hline & Exp & 266.80 & 18. & & 34.87 & 16.19 & $0.000 * *$ \\
\hline & & & & & & & 379 \\
\hline \multirow[t]{2}{*}{ Triglycerides } & Exp & 192.68 & 14.97 & 165.72 & 15.36 & 13.99 & $0.000 * *$ \\
\hline & Con & 31.88 & 5.57 & 32.76 & 5.74 & 2.69 & 0.585 \\
\hline \multirow[t]{2}{*}{ HDL-C } & & 37.28 & & 39.12 & & 4.94 & $0.000 * *$ \\
\hline & & 178.32 & 27.54 & 177.76 & 33.57 & 0.31 & 0.949 \\
\hline & & 134.6 & 27. & & 20.91 & 19.93 & $0.000 * *$ \\
\hline \multirow{2}{*}{ VLDL-C } & Cont & 46.32 & 6.10 & 43.84 & 6.05 & 5.35 & 0.156 \\
\hline & Experimental & 47.48 & 9.04 & 38.96 & 6.69 & 17.94 & $0.000 * *$ \\
\hline
\end{tabular}

**p<0.01. Abbreviations: SD: Standard deviation; HDL-C: High density lipoprotein-cholesterol; LDL-C: Low density lipoprotein-cholesterol; VLDL-C: Very low density lipoprotein-cholesterol

Table 5: Effect of administration of roasted flaxseed powder on cardiac risk factors

\begin{tabular}{|c|c|c|c|c|c|c|c|}
\hline \multirow[t]{2}{*}{ Parameter } & \multirow{2}{*}{$\begin{array}{l}\text { Study group } \\
(n=25)\end{array}$} & \multicolumn{2}{|c|}{ Before } & \multicolumn{2}{|c|}{ After } & \multirow{2}{*}{$\begin{array}{c}\text { Mean } \\
\text { change } \\
(\%)\end{array}$} & \multirow{2}{*}{$p$ value } \\
\hline & & Mean & $\mathrm{SD}$ & Mean & $\mathrm{SD}$ & & \\
\hline \multirow{2}{*}{$\begin{array}{l}\text { Cardiac risk } \\
\text { ratio }\end{array}$} & Control & 8.691 & 1.56 & 8.31 & 1.51 & 4.34 & 0.382 \\
\hline & Experimental & 7.34 & 1.43 & 5.86 & 1.41 & 20.16 & $0.000^{* *}$ \\
\hline \multirow{2}{*}{$\begin{array}{l}\text { Atherogenic } \\
\text { coefficient }\end{array}$} & Control & 7.69 & 1.56 & 7.31 & 1.51 & 4.94 & 0.382 \\
\hline & Experimental & 6.34 & 1.43 & 4.86 & 1.41 & 23.34 & $0.000 * *$ \\
\hline \multirow{2}{*}{$\begin{array}{l}\text { Atherogenicity } \\
\text { index of plasma }\end{array}$} & Control & 0.81 & 0.09 & 0.79 & 0.09 & 2.47 & 0.419 \\
\hline & Experimental & 0.72 & 0.08 & 0.63 & 0.08 & 12.5 & $0.000 * *$ \\
\hline
\end{tabular}

flaxseed powder into diet is feasible and well tolerated, and provides a good source of soluble fiber and ALA, the two key nutrients associated with reduction of CVD risk factors.

\section{REFERENCES}

1. Whaley MH, Brubaker PH, Otto RM. ACSM's. Guidelines for Exercise Testing and Prescription. Baltimore: Lippincott Williams and Wilkins; 2005.

2. Yusuf S, Hawken S, Ounpuu S, Dans T, Avezum A, Lanas F, et al.; INTERHEART Study Investigators. Effect of potentially modifiable risk factors associated with myocardial infarction in 52 countries (the INTERHEART study): Case-control study. Lancet 2004; 364:937-52.

3. Ander BP, Weber AR, Rampersad PP, Gilchrist JS, Pierce GN, Lukas A. Dietary flaxseed protects against ventricular fibrillation induced by ischemia-reperfusion in normal and hypercholestrolemic rabbits. J Nutr 2004; 134:3250-6.

4. Prasad K. Dietary flaxseed in prevention of hypercholesterolemic atherosclerosis. Atherosclerosis 1997;132:69-76.

5. Giada Mde L. Food applications for flaxseed and its components: Products and processing. Recent Pat Food Nutr Agric 2010;2:181-6.

6. Husain S, Muhammad Anjum F, Sadiq Butt M, Sheikh MA. Chemical compositions and functional properties of flaxseed flour. Sarhad J Agric 2008; 24:649-53.

7. Cunnane SC, Ganguli S, Menard C, Liede AC, Hamadeh MJ, Chen ZY, et al. High alpha-linolenic acid flaxseed (Linumusitatissimum): Some nutritional properties in humans. Br J Nutr 1993;69:443-53.

8. Stone H, Sidel JL. Sensory evaluations practices. California: Academic Press; 1993.

9. Otoo E, Asiedu E. Sensory evaluation: The last hurdle in varietal development of yams (Dioscorearotundata, poir) in Ghana. Afr J Biotechnol 2009; 8:5747-54.

10. Srilakshmi B. Food Science. Delhi: New Age International (P) Limited Publishers; 2008.

11. Gopalan C, Rama Sastri BV, Balasubramanian SC. Nutritive Value of Indian Foods. Hyderabad: National Institute of Nutrition, Indian Council of Medical Research; 2004.

12. National Cholesterol Education Program (NCEP) Expert Panel on Detection, Evaluation, and Treatment of High Blood Cholesterol in Adults (Adult Treatment Panel III). Third Report of the National Cholesterol Education Program (NCEP) Expert Panel on Detection, Evaluation, and Treatment of High Blood Cholesterol in Adults (Adult Treatment Panel III) final report. Circulation 2002;106:3143-421.

13. Fossati P, Prencipe L. Serum triglycerides determined colorimetrically with an enzyme that produces hydrogen peroxide. Clin Chem 1982;28:2077-80.

14. Stockbrige H, Hardy RI, Glueck CJ. Public cholesterol screening: Motivation for participation, follow-up outcome, self-knowledge and coronary heart disease risk factor intervention. J Lab Clin Med 1989;114:142-51.

15. Lopes-Virella MF, Stone P, Ellis S, Colwell JA. Cholesterol determination in high-density lipoproteins separated by three different methods. Clin Chem 1977;23:882-3.

16. Friedewald WT, Levy RI, Friedrickson DS. Estimation of the concentration of low-density lipoprotein cholesterol in plasma, 
without use of the preparative ultracentrifuge. Clin Chem 1972;18:499-502.

17. Brehm A, Pfeiler G, Pacini G, Vierhapper H, Roden M. Relationship between Serum Lipoprotein Ratios and Insulin Resistance in Obesity. Clin Chem 2004;50:2316-22.

18. Frohlich J, Dobiásová M. Fractional esterification rate of cholesterol and ratio of triglycerides to HDL-Cholesterol are powerful predictors of positive findings on coronary angiography. Clin Chem 2003;49:1873-80.

19. Harris WS. n-3 fatty acids and serum lipoproteins: Human studies. Am J Clin Nutr 1997;65 (5 Suppl):1645-54

20. Berry EM, Hirsch J. Does dietary linolenic acid influence blood pressure? Am J Clin Nutr 1986;44:336-40.

21. Mozaffarian D, Ascherio A, Hu FB, Stampfer MJ, Willett WC, Siscovick DS, et al. Interplay between different polyunsaturated fatty acids and risk of coronary heart disease in men. Circulation 2005; 111:157-64.

22. Vanharanta M, Voutilainen S, Nurmi T, Kaikkonen J, Roberts LJ, Morrow JD, et al. Association between low serum enterolactone and increased plasma F2-isoprostanes, a measure of lipid peroxidation. Atherosclerosis 2002;160:465-9.

23. Kristensen M, Jensen MG, Aarestrup J, Petersen KE, Søndergaard L, Mikkelsen MS, et al. Flaxseed dietary fibers lower cholesterol and increase fecal fat excretion, but magnitude of effect depend on food type. Nutr Metab 2012;9:8.

24. Wanders AJ, van den Borne JJ, de Graaf C, Hulshof T, Jonathan MC, Kristensen M, et al. Effects of dietary fibre on subjective appetite, energy intake and body weight: A systematic review of randomized controlled trials. Obes Rev 2011;12: 724-39.

25. Henness S, Perry CM. Orlistat: A review of its use in the management of obesity. Drugs 2006;66:1625-56.

26. Alzueta C, Rodriguez ML, Cutuli MT, Rebole A, Ortiz LT, Centeno C, et al. Effect of whole and demucilaged linseed in broiler chicken diets on digesta viscosity, nutrient utilisation and intestinal microflora. Br Poult Sci 2003;44:67-74.

27. Kristensen M, Damgaard TW, Sørensen AD, Raben A, Lindeløv TS, Thomsen AD, et al. Whole flaxseeds but not sunflower seeds in rye bread reduce apparent digestibility of fat in healthy volunteers. Eur J Clin Nutr 2008;62:961-7.

28. Cornish SM, Chilibeck PD, Paus-Jennsen L, Biem HJ, Khozani T, Senanayake V, et al. A randomized controlled trial of the effects of flaxseed lignan complex on metabolic syndrome composite score and bone mineral in older adults. Appl Physiol Nutr Metab 2009;34:89-98.
29. Paschos GK, Magkos F, Panagiotakos DB, Votteas V, Zampelas A. Dietary supplementation with flaxseed oil lowers blood pressure in dyslipidaemic patients. Eur J Clin Nutr 2007;61:1201-6.

30. Begg DP, Sinclair AJ, Stahl LA, Premaratna SD, Hafandi A, Jois $\mathrm{M}$, et al. Hypertension induced by omega-3 polyunsaturated fatty acid deficiency is alleviated by alpha-linolenic acid regardless of dietary source. Hypertens Res 2010;8:808-13.

31. Pan A, Yu D, Demark-Wahnefried W, Franco OH, Lin X. Meta-analysis of the effects of flaxseed interventions on blood lipids. Am J Clin Nutr 2009;90:288-97.

32. Bassett CM, McCullough RS, Edel AL, Patenaude A, LaVallee RK, Pierce G. The $\alpha$-linolenic acid content of flaxseed can prevent the atherogenic effects of dietary trans fat [abstract]. Am J Physiol Heart Circ Physiol 2011;301:H2220-6.

33. Lucas EA, Mahajan SS, Soung do Y, Lightfoot SA, Smith BJ, Arjmandi BH. Flaxseed but not flaxseed oil prevented the rise in serum cholesterol due to ovariectomy in the Golden Syrian hamsters. J Med Food 2011;14:261-7.

34. Prasad K. Hypocholesterolemic and antiatherosclerotic effect of flax lignan complex isolated from flaxseed. Atherosclerosis 2005;179:269-75.

35. Saman K, Rosita J, Amin I. Effect of raw and heated flaxseed (Linum Usitatissimum L). On blood lipid profiles in rats. Int Journal of Appl Sci Technol 2011;4;84-9.

36. Martirosyan DM, Miroshnichenko LA, Kulokawa SN, Pogojeva AV, Zoloedov VI. Amaranth oil application for heart disease and hypertension. Lipids Health Dis 2007;6:1-4.

37. Shen GX. Lipid disorders in diabetes mellitus and current management. Curr Pharmaceut. Anal 2007;3:17-24.

38. Assmann G, Gotto AM Jr. HDL cholesterol and protective factors in atherosclerosis. Circulation 2004;109 (23 Suppl 1):III8-14.

39. Usoro CA, Adikwuru CC, Usoro IN, Nsonwu AC. Lipid profile of postmenopausal women in Calabar, Nigeria. Pak J Nutr 2006;5:79-82.

40. Onat A, Can G, Kaya H, Hergenc G. Atherogenic Index of Plasma ( $\log 10$ triglyceride/high-density lipoprotein cholesterol) predicts high blood pressure, diabetes and vascular events. J Clin Lipidol 2010;4:89-98.

41. Daun JK, Barthet VJ, Chornick TL, Duguid S. Structure, composition, and variety development of flaxseed in human nutrition. USA: AOCS Press; 2003.

42. Muir AD. Flax lignans - analytical methods and how they influence our understanding of biological activity. J AOAC Int 2006; 89:1147-57.

Biomed J Vol. 37 No. 6

November - December 2014 